\title{
Developing Reading Fluency: Insights into the Effective Fluency Instruction
}

Received: 14/11/2019 ; Accepted: 10/12/2019

\section{Abstract}

Reading fluency allows the reader to focus his cognitive attention on gaining meaning from what is read. Because of its strong impact on comprehension, researchers and educators' interest is centered on testing the best conditional practices that would sustain the development of reading fluency and provide an indirect support to reading comprehension. On one hand, this descriptive exploratory study digs deep on the existing literature on the functional relationship between reading fluency and comprehension; and on the other hand, it sheds light on the different direct fluency instructions proved effective since Samuels' repeated reading (1979) to the most recent ones: fluency integrated instructional routines. As the effect of the combined fluency instructional strategies is higher than the effect of a fluency instruction working individually, we recommend the Fluency Oriented Reading Instruction as the most effective literacy program for EFL learners.

Keywords: Automatic processing; comprehension; EFL learners; fluency based instruction, reading fluency.

\section{Radia Bouguebs *}

Maître Conférence "B" ENS “Assia Djebar", Constantine, Algeria

\section{Résumé}

La fluidité en lecture permet au lecteur de concentrer son attention sur le sens de ce qui est lu. En raison de son impact sur la compréhension, le développement de cette compétence stimule les chercheurs à tester les meilleures interventions pédagogiques qui contribuent à son développement. D'une part, ce travail est une étude descriptive approfondit de la littérature existante sur la relation fonctionnelle entre la fluidité en lecture et la compréhension; et d'autre part, elle presente les différents instructions pédagogique de la fluidité qui se sont révélées efficaces, depuis "Repeated Reading" de Samuels (1979) aux plus récentes: les routines d'enseignement intégrées de la fluidité. Parce que l'effet de ces dernières est supérieur, nous recommandons "Fluency Oriented Reading Instruction" dans laquelle un nombre de stratégies d'enseignement de fluidité sont suivies dans un cycle hebdomadaire comme étant le programme le plus efficace pour les apprenants.

Mots clés Traitement automatique; compréhension; instruction de lecture basée sur la fluidité; la fluidité en lecture.

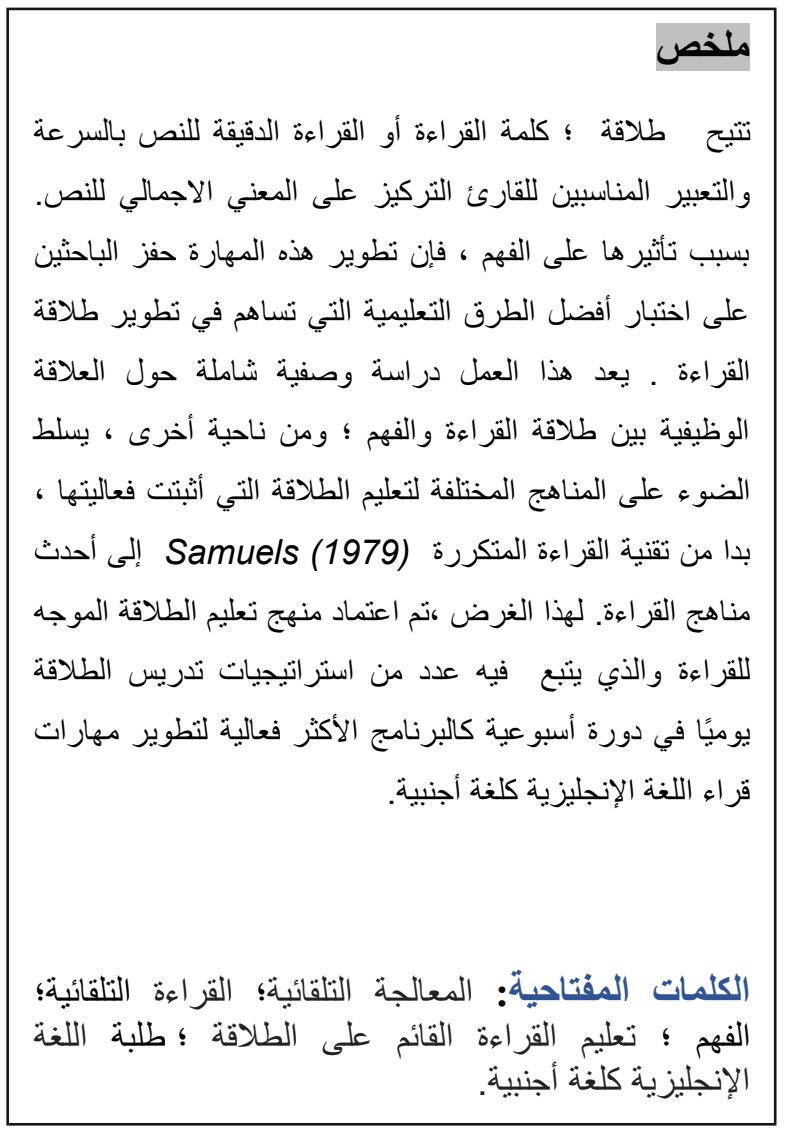

* Corresponding author, e-mail: bouguebs@yahoo.fr 


\section{I- Introduction}

Reading and making meaning from the print is the reader's ultimate goal. The latter is achieved when the reader goes beyond the process of accurately recognizing word to a proceeding where decoding is almost accurate and automatic. A level of expertise referred to as reading fluency. In English as a Second and as Foreign Language (L2/EFL) context, the readers' emphasis on word recognition is done at the expense of meaning extraction from the print resulting in a comprehension deficiency. Developing this reading skill becomes a subject of interest among scholars and educators when the latter was recognized as a level of expertise beyond word recognition accuracy that may facilitate comprehension in English as First Language (L1) as well as in English as a Second and as Foreign Language (L2/EFL) context.

Instead of letting this talent develops by itself without providing a direct instruction and making the skill under a constant check where the results may be positive or negative, embedding fluency instructions in all reading instructional programs right from the beginning of learning to read turns into a literacy goal (Samuels, 1979; Samuels, 2002). As a matter of fact, Investigating for the effective fluency instruction that focuses on reading with understanding, rather than simply reading quickly has stimulated scholars and researchers to test the best conditional practices that both would sustain the development of reading fluency and provide an indirect support to reading comprehension (Grabe, 2010).

Even though there is a consensus among researchers that fluency is an essential component of skilled reading, proclaim Kuhn et al. (2006), theoretical and practical questions regarding the ways in which instruction can best be implemented to facilitate fluent reading remain questionable. Previous research can only be considered as first step towards a more profound understanding of fluency development; yet recent theoretical developments have centered around the kind of instruction that can contribute in fostering readers' ability to group the words of the text into appropriate phrases and clauses, to read at a conversational rate as if they are speaking, to both automatically decode and focus their attention on gaining the meaning of the text, and to engage in a continuous self-monitoring. Since the time the LaBerge and Samuels' seminal article (1974) was published, fluency based instruction turns into a field of interest for researchers.

Adding to the review of the prevailing debates about the definition of reading fluency, fluent readers' reading behaviour, and the relationship between fluency and comprehension, the scope of this study is limited to shed light on the different direct fluency instructions starting from Samuels' (1979) classical repeated reading to the most recent ones: fluency integrated instructional routines. As the effect of the combined fluency instructional strategies is higher than the effect of a fluency instruction working individually, we recommend the Fluency Oriented Reading Instruction routine where a multiple number of effective fluency instruction strategies are followed daily in a week cycle as the most effective fluency instruction program.

\section{II- Literature Review}

\section{II.1. Defining Reading Fluency}

The interest provided to reading fluency since the publication of the seminal article of LaBerge and Samuels 1974 makes from this concept a field of investigation where the attention of scholars and researchers is focused on providing a fitful description to the term. As the emphasis of what constitutes this latter has changed over time, agreeing on a single definition was a difficult task Rasinski (2006a).

Reading fluency is identified as "freedom from word identification problems that might hinder comprehension in silent reading or the expression of ideas in oral reading" (Hodge and Harris, 1995, p. 85). So, besides overcoming word recognition problems and manifesting an adequate comprehension when reading silently, or orally; 
some experts assume that effective and fluent reading is mainly distinguished by the reader's ability to read in phrases with appropriate intonation and prosody (Kuhn et al., 2010). No fluent reading is complete, unless the reader demonstrates an effortless reading where his reading ability goes beyond recognizing words quickly in the text to reading and using expression manifesting an appropriate understanding of what is read. This implies that reading fluency is a multidimensional skill where one dimension targets reading accuracy, the second dimension addresses reading automaticity, and the third dimension reflects reading prosody (Rasinski, 2004). These fluency sub-skills when combined together (accuracy, automaticity, and prosody) indicate the students' fluency progress (Samuels, 2006). Thus, manifesting all the bellow listed subskills while reading would result in a full description of what fluency is.

“Fluency as Word Reading Accuracy" is manifested via the reader's ability to sound out the words in a text with minimal errors (Rasinski, 2004). Accuracy is regarded as a precondition for fluency (Rasinski \& Padak, 2013) because the reader's ability to recognize or decode words correctly would facilitate his understanding and correct interpretation of what is being read (Hudson et al, 2005).

"Fluency as Reading Automaticity" is demonstrated in the reader's automatic recognition of words (Rasinski, 2004). This fluency precondition refers to the reader's talent to decode words without conscious thought both accurately and rapidly. Automaticity is often viewed as the essential component of fluency (Samuels, 1997, 2002) because, most often, reading fluency is assessed by measuring students' reading rate.

"Fluency as Reading Prosody" is displayed through the reader's capability to use the appropriate prosodic features of speech. Prosody, or reading with expression that is used interchangeably with the "the music of speech" or "the music of the language" (Kuhn et al., 2010) is the ability to project the tonal aspects of speech on to print making from the reader's reading sounds natural as if he is speaking.

Reading fluency is, then, manifested via the reader's ability to encompass an accurate word recognition known as "accuracy", a reading at a conversational rate known as the "rate/pace" of reading, and a reading with a proper expression referred to as "prosody".

\section{II.2. Approaching Fluency via Automatic Processing Theory}

The LaBerge and Samuels' Automatic Information Processing theory (1974) suggests that to free up the reader's cognitive resources to focus on comprehension of text, word recognition and phrasing should be done at an automatic level. This model of reading assumes that reading words fluently must occur before comprehension is possible. As reading requires both decoding and comprehension, beginner readers have to shift their cognitive attention between the two which may result in diminishing from the needed attention to the second skill: comprehension. Developing the reader's ability to read for meaning is quite impossible until he has learned to identify words and letters automatically (Samuels, 2002; 2012). Thus, the shift from the decoding stage to the automatic word recognition allows readers to focus their full attention on getting the meaning of what was decoded. And when the reader's total cognitive attention is focused on the decoding stage which is the case of less fluent readers, comprehension may be hindered (Rasinski et al, 2009).

When explaining the transition from beginner reader to a skilled one, the LaBerge and Samuels' theory makes certain assumptions. According to Samuels ( 2012, p. 4), (a) it is assumed that human mind has a limited capacity to perform difficult tasks; and (b) to perform difficult tasks such as recognizing words and understanding them, this mental effort consumes some of the limited cognitive capacity of the mind. To release from the mind' limited capacity, (c) with continuous practice overtime, this amount of effort decreases gradually. At last, (d) when the amount of the mental effort drops sufficiently, that person can engage in a new task in parallel. These rules facilitate the 
description of a fluent reading (ibid). Hence, LaBerge and Samuels' Automatic Information processing theory main assumptions sets the ground for effective fluency instruction based classroom practices.

\section{II.3. Fluent vs Non-fluent Reading Behaviour}

The coordination between fluency components in an oral reading which is manifested via a fluent expressive reading is the common defining feature of good readers. However, the lack of fluency that is a common characteristic of poor readers (Hudson et al., 2005) is the result of a deficiency in one of the fluency components (accuracy, speed, or prosody). Non-fluent readers read in a labored, disconnected fashion with a focus on decoding at the word level which makes comprehension difficult (ibid). Opposite to, comprehending what is being read is one of the main distinguishing characteristics of fluent readers (Rasinski, 2006a; Kuhn et al., 2010; Bouguebs, 2017). When observing their reading behaviors, one can easily distinguish fluent from non-fluent readers.

"Eye movements provide behavioral indicator of reading fluency" assert Valle et al., (2013, p. 172). Being apt to recognize words automatically or by sight which is manifested via the reader's eye movement when exposed to the print is a major characteristic of a fluent reader. The ability to extract several words at a single fixation is due to the fact that fluent readers have developed a strong visual memory which facilitates for them the automatic recognition of words. Less skilled readers, however, are characterized by short saccadic eye movements (Samuels, 1979, p. 363). This implies that they are relying on letter- by- letter processing; and fixation of a long duration resulting in long information processing time which hinders them from focusing on the comprehension of what is being read because their full attention is centered on the decoding stage. This excess of fixations and regressions at the level of word recognition will result in the reader's expenditure of more time and energy leading to a decline in reading rate and a discomfort in reading. "Therefore, eye movement data during oral reading may reveal important information about reading processes, particularly for low-skilled readers" (Barnes et al., 2017, p.182).

More fixations on visual information that decrease the speed of reading describe the general state of a non-fluent reader. However, it can also be the case of fluent reader when encountering a difficult passage. Because they are better at seeing a word in a single eye fixation, fluent readers do not need as many regressions (Hudson et al., 2005); yet, when encountering an unfamiliar word, or a difficult passage to read; the number of fixations increase; consequently, the reading speed goes down ( Samuels, 1997). Simply because the fluent reader is forced to use more visual information to try to understand what he reads.

By making appropriate manipulation and use of the prosodic features in their reading, fluent readers are manifesting their understanding of what is read. Adding to their talent in decoding and translating punctuation into speech; fluent readers include the ordinary rise and fall of pitch in ordinary conversation (Schwanenflugel et al., 2004). Opposite to, less fluent are incapable to transfer the prosodic elements that occur naturally in speech onto written text (Hudson et al., 2005). Their reading is either in a word by word manner, in a monotonous tone, or words are grouped in ways that do not parallel spoken language.

\section{II.4. Reading Fluency a Bridge to Comprehension}

The fact that reading comprehension is more than simply accessing the meanings of the individual words in the text, it is conditioned with how much the reader is able to automatically recognize words accurately and efficiently (LaBerge \& Samuels, 1974). Developing a control over surface level text processing (automatic processing) is vital for a successful comprehension to occur (Rasinski, 2004) because it enables the reader to center his cognitive attention on getting to the deeper levels of meaning embedded in the text. 
Investigating the type of relationship that might exist between fluency and comprehension garbs researchers' attention mainly after proving that these reading skills, fluency and comprehension, correlates one with another (Samuels, 1997, 2002; Allinghton, 2006; Rasinski, 2004; Rasinski \& Padak, 2013). Because the association between these two variables is somehow complex to determine (Pikulski \& Chard, 2005), the guiding questions to any investigator are whether fluency leads to, or results from comprehension. Most researchers agree that when fluency is developed, comprehension is the expectation (Grabe, 2010). Fuchs et al. (2001) study has shown that there is a surprisingly strong relationship between oral passage reading fluency and reading comprehension measures. Along the same line of thought, Klauda and Guthrie (2008) confirm that oral passage reading fluency significantly accounted for comprehension abilities. However, when readers are not fluent, comprehension suffers (Rasinski et al., 2009).

Investigations in this field are multiple between those who affirm that the relationship between fluency and comprehension is unidirectional. Either fluency is the result of good comprehension (Anderson et al., 1990), or it is the increasing fluency that leads to deeper comprehension. Anderson and his associates (1990) found that students in highly fluent groups experience a smooth and continuous reading that promotes the development of a connected representation of the story. Notwithstanding, in their review to fluency research, Stecker and his colleagues (1998) evidenced that fluency is both a contributor to and a product of comprehension. This assumption is backed by the fact that comprehension and fluency share a reciprocal causal relationship (Cited in: Pikulski \& Chard, 2005:510). Bearing a reciprocal relationship rather than unidirectional one implies that fluency and comprehension are interrelated. A very strong research and theoretical base indicates that while fluency in and of itself is not sufficient to ensure high levels of reading achievement; fluency is absolutely necessary for that achievement because it depends upon and typically reflects comprehension" (Pikulski \& Chard, 2005, p. 517). Fluent readers reflect the meaning of the text via reading at a conversational rate manifesting the author's message via their respect to the text prosodic features. Reading as if speaking proves that the reader is not only reading fluently; however, he is reading with a profound comprehension of what is read.

\section{II.5. Fluency Based Instruction: Repeated Reading and its Variations}

The way researchers and educators in the world of reading approached the instructional methods for developing reading fluency starts to emerge since The LaBerge and Samuels's Automatic Processing Theory to reading (1974). Since this latter did not provide any practical implications on how to develop the reader's automatic word recognition, Jay Samuels put the theory to test in 1979. Following the recommendation of this theory, he developed a method which he named "the Repeated Reading" (RR) method.

This fluency strategy requires "the rereading a short meaningful passage several times until satisfactory level of fluency is reached. Then the procedure is repeated with new passage" explains Samuels (1997, p. 379). Instead of having our students encounter a new selection daily, a better method to building fluency would be to have them read the same selected passage several times until they reach a predetermined fluency criterion. His work on this method revealed that when students orally practiced a piece of text they improve on their reading of that text - rate, accuracy and comprehension. Furthermore, these gains are transferred to new unpracticed texts. Based on the assumption that the automatic word recognition may be developed through multiplying the reader's exposure to the print, the world of reading has been immersed by a wide range of intervention methods designed to develop this reading skill. 
“Assisted reading" or Guided repeated reading is a kind of a rereading strategy where the student listens to a model of a fluent reading provided by his/her teacher or the adult reader. The teacher can use a live model, or he can use a tape assisted reading model. The student reads first the same passage aloud and the teacher or the adult provides help when necessary. Each student is helped during his oral reading to identify problem words. Next, he rereads the passage more times until s/he can read it comfortably with ease and less errors, i.e.; fluently.

“Partner Reading” is another rereading technique where pairs of students take turns reading and rereading aloud the same passage to each other. This fluency strategy that is referred to as scripted cooperative learning strategy is often used in classrooms to promote the development of fluent and automatic reading skills (Meisinger et al., 2004). During this activity, the student is required to read a short passage to a partner who in turn gives feedback when needed; then, the partners switch roles to avoid frustration.

During “Choral Reading” instruction, small groups listen and then repeat to a fluent model. Everyone in the group reads the same text together at the same time. After the teacher provides a model of a fluent reading and discusses with his students the qualities of this fluent reading -the manipulation of rate, the appropriate phrasing, and expression- a group of students is assigned to echo chorally. The students in that group are asked to keep their voices together and make them sound as much like the model as possible. Or they can vary in the practice of choral reading by reading in unison. Teacher and students read simultaneously, rather than sequentially. Studies proved that students of all ages tend to enjoy this strategy (Housel, 2010) because reading in a group and in one voice offers them the possibility to develop their fluent reading through learning from each other under the guidance of the instructor.

“Echo Reading” as another variation of RR used with a whole group, small group, or an individualized instruction aims at increasing oral reading fluency (Stahl \& Heubach, 2005). For a successful echo reading, it is recommended that the teacher provides a model of a fluent expressive reading. After that, he reads one line at a time and asks the class to echo read the same line before going on to the next line (ibid). When the student practice this strategy, he repeats "echoing" not only the words accurately but the intonation (Hapstak \& Tracey, 2007).

"Readers' Theatre" or script reading is one more re-reading procedure. After providing students with the script several days in advance and asking them to read and reread their assigned parts prior to a final performance, they stand in front of an audience, usually made up of their classmates and reads from script (Rasinski, 2003). Usually the scripts used to practice this fluency strategy are derived from books rich in dialogues. Their role during this fluency strategy is limited to a number of steps (Tyler \& Chard, 2000). Students read the text silently or with a peer in paired reading; then they read it again by taking turns in reading different roles to get involved in the characters' emotions, feelings, and different personalities. Next, they read the text again when they have chosen the role they wish to portray in the context many times (more rehearsals). At last, they read the text a final time, script in hand, by presenting their interpretation of the play to the class or some other appreciative audience (ibid, $p$. 166-167). The teacher's role is to incorporate sound instructional practices into the activity by discussing characters and setting and by encouraging students to predict what will happen next and then prompting them to check their predictions

All the above listed fluency strategies require oral reading that start with a model of a fluent reader, immediate feedback (teacher's assistance), and most importantly they require repetition of the reading until the text is read accurately with an appropriate speed and a proper expression, fluently. 


\section{II.6. Synthesizing Reading Fluency Instructions}

Since 1974, several research studies have proved that the RR is the best method in improving students' automaticity in reading (Samuels, 1979, 2002; Hudson et al., 2005). Despite this gained importance, a fluency instruction is judged incomplete if prosody and comprehension skills are not prominent as accuracy and rate. Unintentionally, whenever the repeated reading is implemented, both students and teacher focus on developing automaticity even though the other fluency components are the most targeted during the instruction. In study intended to develop students' expressive reading and not speed (Martinez et al., 1999), results revealed that students in the Readers Theater group made remarkable improvement in reading rate than the control group. One way to overcome these problems is to provide fluency strategies where "the instruction on accuracy, automaticity, and prosodic reading occur in unison-in an integrated and synergistic manner" (Rasinski, 2006r, p. 705). How is it possible to make from the RR instruction stress on reading rate, accuracy, and prosody, if by nature the method was created to just develop automatic word recognition?

Nothing is impossible, if the fluency instructional strategies (echo reading, choral reading, partner reading...etc) work together within the same instruction. For Rasinski (2013), if these latter are combined in an integrated way within a reading program "the potential impact on fluency and overall reading proficiency is even greater" (Rasinski, 2013 , p.4). As the effect of the combined fluency instructional approach is higher than the effect of a fluency instruction working individually, a call for integrated instructional routines is vital.

\section{II.7. Fluency Instructional Routines Characteristics}

A fluency instructional routine is "a set of instructional activities aimed at developing a particular skill in reading that is implemented on a regular schedule, usually on a daily or weekly basis" (Rasinski et al., 2008s, p. 10). Every instructional routine begins with the teacher explaining and modeling the task "I do"; then, the teacher and students practice the task together, followed by the students practicing that task with scaffolding from the teacher "We do"; and at last, students practice the newly learned skill independently "You do" (Kosanovich, 2012). Integrated fluency instructional routines are fluency lessons where a multiple number of effective fluency instruction such as repeated reading method, partner reading, echo reading, choral reading are followed daily in a week cycle. The main target of these routines is to sustain students in developing accurate, automatic word recognition and prosody along with an appropriate understanding of what is read (Stahl \& Heubach, 2005). Despite the differences between these approaches to fluency instruction; in fact, they share in common four aspects: reading a connected text, modeling, scaffolding, and repeated exposure to the same text.

"Reading connected text" instead of reading short passages. Previous fluency approaches such as the Round Robin that rely on making individual students take turns in reading small portions of the text (a paragraph or two) each day do not provide enough opportunities for a fluency practice (Kuhn \& Levy, 2015). Additionally, when the whole text is broken down into portions, the comprehension becomes more difficult to grasp. Accordingly, reading fluency development can be achieved via multiplying the student's exposure to reading connected texts instead of short passages (Stahl \& Heubach, 2005).

"Modeling" is a direct/explicit teaching strategy where a direct demonstration is presented to students on how to use their learning (Rupley et al., 2009). Students must hear fluent reader's model reading and must be given time to improve their delivery with strong adult coaching (Tankersley, 2003). By listening to good models of fluent reading, students can hear how a reader's voice makes sense of the text (Martinez et al., 2002). By observing the model, the learner can form an idea about the appropriate performance of a fluent reading; and on later occasions this coded information serves as a guide for action in that he puts into action what he has learned from the model. 
"Scaffolding" is an essential component of direct instruction. Scaffolding incorporates a variety of techniques; it can be general aids such as modeling or demonstrating a strategy, or they can be specific aids used to teach a strategy (Rupley et al., 2009). In one of the scaffolding techniques, speculates Kosanovich (2012), a teacher might provide more information, modeling, guidance, or feedback during the instruction. In another technique called "scaffolding suggestion for errors", the teacher asks individual student model the task again with a different word or model fluent reading by his own. This last task is included in the last part of each Instructional Routine (ibid, p.8). In brief, scaffolding releases the learning responsibility from the teacher to the students.

"The repeated exposure to the text" is the backbone in any instruction that aims at developing reading fluency and comprehension. As recommended by Automaticity theory, students can focus on comprehension when they develop the automatic recognition of words. This skill is shaped when the number of the exposure to the print is multiplied. A set number of rereading strategies such as echo reading, choral reading and partner reading are integrated together to form the body of the instructional routines (Stahl \& Heubach, 2005).

\section{II.8. Types of Fluency Instructional Routines}

“Oral Recitation Lesson" (ORL) that is a fluency developmental lesson designed by Hoffman and Crone (1985) incorporates direct and indirect instruction during small-group reading. This fluency instructional procedure represents a framework where a basal reading lesson is effectively implemented over the course of a week (Kuhn et al., 2006). After selecting a reading material that lends itself for performance (conversational texts), an ORL starts (Nichols et al., 2008). Since the lesson is both fluency and comprehension based, students are directly instructed in these skills. The teacher reads the story to his students providing a model of a fluent oral reading that is immediately followed by a comprehension instruction. After that a class discussion is raised where students are asked to identify the story elements such as the main theme, characters, main events, setting...etc. By the end of the lesson, they use the information to write the summary of the story.

“Fluency Developmental Lesson” (FDL) was designed as an intervention method for use with students experiencing difficulties in fluency and learning to read. This type of lessons is a direct fluency instruction model where poetry is incorporated as a means of maximizing students' fluency and comprehension development within a 10-15 minute lesson (Rasinski et al., 2008t). The FDL combines several aspects of effective fluency instruction: choral reading, paired reading, and repeated readings, in order to focus on fluency and reading comprehension in a relatively short period of time. During the 15 minutes per day of reading practice, students and their teachers work with a daily text following some steps. The first lesson of the week starts by the prediction of text that is followed by a modeled reading performed by the teacher. When the teacher provides a live model of a fluent reading for students, the responsibility for reading the text is gradually released from the teacher to the students via the repeated reading practices such as choral reading and paired reading. Next, a class discussion is raised to assess students' initial understanding of the text. Just after, they engage in fluency practice choral reading, paired reading. Adding to the in class tasks, the students perform the text, and engage in word study and further practice of the passage at home.

“Fluency-Oriented Reading Instruction" (FORI) is designed by Stahl's and Heubach (2005) for wide classroom instruction. This new instructional routine that is judged to be effective as a whole class fluency instructional routine (Shwanenflugel, 2008) emerged as result to the benefits drawn from the ORL. One of its initial goals is the provision of heavily scaffolded reading instruction to ensure that students have multiple opportunities to read each selection. Stahl and Heubach assume that by 
incorporating extensive amounts of support or scaffolding as part of the overall lesson plan, the learners would benefit from instruction within the classroom. FORI is guided by five main objectives: (a) lessons are to be comprehension centered even when fluent reading is being focused on during the instruction, (b) materials to be used during the training should be graded at the learners' instructional level (texts that are neither easy nor difficult), (c) students are supported in their reading through the varying forms of the repeated reading strategies (assisted reading, choral reading, echo reading...etc), (d) no FORI program is complete without partner reading practice (providing students with the opportunity to read connected texts within a socially supportive context), and (e) supervising students' at home reading via the regular check of this activity. This objective is attained through raising students' awareness that any practice they are undertaking is for the sake of facilitating their comprehension of the material at hand. By providing direct explicit instruction, FORI allows the reader not only to experience accuracy, automaticity, and prosody growth; however, the main benefit he can gain under this instructional classroom setting is comprehension progress as well.

\section{II.9. Recommending FORI for EFL Learners}

FORI expends the pedagogical implications of the Automatic Processing Theory (1974). As stated previously, the main objective of any fluency instruction approach is to put into practice the recommendations of this theory. One of which is that multiplying the reader's exposure to the print is the most successful way for developing his automatic word recognition which in turn enables him to devote his full cognitive attention to generating the meaning of the text. Since then all fluency instructions call for the repeated reading strategy. However FORI starts from the principle that reading fluency improves not only by multiplying the readers' opportunities to practice reading connected text (RR Strategies); rather, instructors should insist on the fact that the repeated reading practice is heavily scaffolded.

FORI framework incorporates an extensive support or scaffolding as part of its overall lesson plan. By providing sufficient instructional support in the form of immediate feedback and modeling, students gain benefits from the in-class reading instruction as well as the at home reading instruction and experience automatic and expressive reading (Stahl \& Heubach, 2005). This feature that characterizes the FORI is the one that makes this program distinct from the above listed fluency strategies. The priority given to FORI stimulated researchers to examine the effectiveness of this integrated instructional routine in new settings and with new conditions.

FORI reading program is proved as an efficient fluency instruction and as an effective literacy program either in L1 setting (Stahl \& Heubach, 2005; Kuhn et al., 2006; Thornton, 2008; Turner, 2010), or in EFL setting (Bouguebs, 2017). Kuhn and his associates (2006) observed the effects of FORI and Wide- Reading Instruction on reading fluency of second-grade students. By the end of the school year, the two experimental groups manifested similar progress in reading fluency and in reading comprehension skills as compared to control group. In another investigation, Thornton (2008) tested the efficiency of modified-FORI on 65 African American students. Results demonstrated the positive effects of this integrated fluency instructional routine on oral reading fluency scores and attitude towards reading. Within the same scope, Turner (2010) tried to examine the effectiveness of FORI in promoting reading fluency for $2^{\text {nd }}$ grade students. FORI evidenced as a useful procedure for reading instruction because students made significant improvements in word efficiency and reading comprehension. Additionally, in a study undergone at the department of English in the Ecole Normale Supérieure of Constantine, Bouguebs (2017) tested the efficiency of FORI reading program on 30 second year EFL students. Quantitative data revealed that the regular use of the FORI results in a significant statistical improvement in automaticity, prosody, and comprehension retelling. Besides fluency and comprehension growth, the qualitative findings (students' interviews) certified that FORI reading instructional routine loaded students with self-confidence and assurance to go further because some of their learning needs such as reading as if speaking and engaging in reading books were satisfied (Bouguebs. 2018). These numerous benefits 
increased students' awareness towards the importance of FORI not only for them as EFL learners, or as future teachers; but for all second year English students.

The integrated and synergistic manner in which fluency components are targeted makes from FORI the most effective fluency instruction. Good fluency training is the one that targets the three components of fluency at the same time by giving them the same portion of importance both during the instruction and the assessment. The manipulation of a multiple number of fluency strategies such as partner reading, echo reading and choral reading during which students' awareness towards the prosodic features of the practiced text (how a fluent reading sounds) is raised both during the instruction and during the assessment makes from FORI a complete fluency instruction. The teacher's role during FORI is to provide a model and makes his students distinguish the factors that characterize a fluent reading- appropriate speed, accurate word recognition, and adequate expression. To facilitate this task both for teachers and students, FORI implements reading materials that are mainly dialoguesbased creating, by then, more opportunities for oral demonstration and modeling in the instruction.

FORI ameliorates comprehension skills and encourages students to engage in a critical reading. Since comprehension is at the forefront, the implementation of some comprehension strategies during reading like predicting, making inferences, and drawing conclusions allow students to experience improvement in their comprehension skills (Bouguebs, 2017). Many participants in the FORI conditions reaffirmed that they adopted a new way of reading (Bouguebs, 2018). Reading and interacting with the author through questioning and stating hypothesis reflect a progress in the students' higher order thinking skills (ibid). And it is the appropriate teaching strategies and learning environments that facilitate their growth (King et al., 1998).

\section{III- Conclusion}

Opting for an effective fluency instruction that fosters the progress of fluent readers has always been the objective of fluency development instruction since the LaBerge and Samuel's 1974 seminal article. Since the effect of the combined fluency instructional routines in fostering readers' ability to group the words of the text into appropriate phrases and clauses, to read at a conversational rate as if they are speaking, to both automatically decode and focus their attention on gaining the meaning of the text, and to engage in a continuous self-monitoring is higher than the effect of a fluency instruction working individually, a call for integrated instructional routines is vital. Due to the fact that the structure of FORI and its emphasis both on fluency and comprehension development ranks it among the recognized effective approaches to literacy instruction; EFL teachers, course designers and researchers are requested to take into account the importance of this integrated fluency instructional routine as a key in improving EFL learners' reading skills. 


\section{References}

[1]. Anderson, R. C., Wilkinson, A. G. \& Mason, J. M. (1990). A micro analysis of the small group guided reading lesson: Effects on an emphasis on global story meaning. Centre of the Study of Reading, Technical Report, No.519, University of Illinois

[2]. Barnes, A.E., Kim, Y-S., Tighe, E., \& Vorstius, C. (201\&). Readers in adult basic education: components, skills, eye movements, and fluency. Journal of Learning Disabilities, 50( 2), 180-194.

[3]. Bouguebs, R. (2017). The Effect of fluency oriented reading instruction on EFL students' reading fluency and comprehension. Revue Science Humaines, Vol A (47), $59-73$

[4]. Bouguebs, R. (2018). Fluency oriented reading instruction and repeated reading effects in enhancing reading fluency and comprehension: the case of second year EFL students at the teacher training school of Constantine. Unpublished Phd thesis. University of Constantine-1-, Constantine, Algeria.

[5]. Fuchs, L. S., Fuchs, D., Hosp, M. K. \& Jenkins, J. (2001). Oral reading fluency as an indicator of reading competence: theoretical empirical and historical analysis. Scientific Studies of Reading, Vol5, No.3 ,239-256.

[6]. Grabe, W. (2010). Fluency in reading: thirty five years later. Reading in Foreign Language, 22(1), 71-83.

[7]. Hapstak, J. A. \& Tracey, D. H. (2007). Effects of assisted repeated reading on Students of varying reading ability: a single subject experimental research study. Reading Horizons Journal, 47 (4), 315-334.

[8]. Harris, T. L. \& Hodges, R. E. (1995). The literacy dictionary: the vocabulary of reading and writing. The International Reading Association.

[9]. Housel, D. G. (2010). Strategies for building fluency. Shell Education Publishing, Inc.

[10]. Hudson, R. F. , Pullen C.P. \& Lane, H. B.(2005). Reading fluency assessment and instruction: what, why and how? The International Reading Association.702-714.

[11]. King, F. J. , Goodson, L., \&Rohani, F. (1998). Higher-order thinking skills: definitions, strategies, and assessment. Retrieved from: http://www.cala.fsu.edu/

[12]. Klauda, S. L. \& Guthrie, J. T. (2008). Relationships of three components of reading fluency to reading comprehension. Journal of Educational Psychology, 100 (2), 310321.

[13]. Kosanovich, M. (2012).Using instructional routines to differentiate instruction. A guide for Teachers. Portsmouth, NH: RMC Research Corporation, Center on Instruction.

[14]. Kuhn, M. R. , Schwanenflugel, P. G. , Morris, R. D., Morrow, L.M., Woo, D.G., Meisenger, E.B., Savcik, R.A., Bradley, B.A.\& Stahl, B.A. (2006). Teaching children to become fluent and automatic readers. Journal of Literacy Research, 38(4), 357-387, Lawrence Erlbaum Associates.

[15]. Kuhn, M. R, Schwanenflugel, P. G \& Meisenger, E.B. (2010). Aligning Theory and Assessment of Reading Fluency: Automaticity, Prosody and Definitions of Fluency. Reading Research Quarterly, Vol 45, No. 2, 230-251.

[16]. Kuhn, M.R. \& Levy, L. (2015). Developing fluent readers: teaching fluency as a foundational skill. Guilford Press

[17]. LaBerge, D. \& Samuels, S. J. (1974). Toward a theory of automatic information process in reading. Cognitive Psychology, 293-323.

[18]. Martinez, M. , Roser, N. L. \& Strecker, S. (1999). I never thought I could be a star: a readers theater ticket to fluency. The Reading Teacher, Vol 52, 326-334. 
[19]. Meisinger, E. B, Schwanenflugel, P. J, Bradely, B. A. \&Stahl, S. (2004). Interaction quality during partner reading. Journal of Literacy Research, Vol 36, No. 2, 111-140.

[20]. Nichols W. D., Rupley, W. H. \& Rasinski, T. (2008). Fluency in learning to read for meaning: going beyond repeated readings. Literacy Research and Instruction, Vol 48, No. 1, 1-13.

[21]. Pikulski, J. J. \& Chard, D. J. (2005). Fluency: bridge between decoding and reading comprehension. The Reading Teacher, Vol. 58, No. 6, 510-519.

[22]. Rasinski, T. (2003). The fluent reader: oral reading strategies for building word recognition, fluency, and comprehension. Teaching Resources/ Scholastics

[23]. Rasinski, T. (2004). Assessing reading fluency. Pacific Resources for Education and Learning. Honolulu. Hawaii.

[24]. Rasinski, T. (2006). A brief history of reading fluency. In Samuels, S. J, \& A. E, Farstrup (eds), What research has to say about fluency instruction, International Reading Association. 70-93.

[25]. Rasinski, T. (2006). Reading fluency instruction: moving beyond accuracy, automaticity and prosody. Issues and trends in literacy, The Reading Teacher, 59(7), 704-709.

[26]. Rasinski, T., Rupley, W. H. \& Nichols, D. (2008). Synergistic phonics and fluency Instruction: The magic of rhyming poetry! The NERA Journal, Vol 44, No. 1, 9-14.

[27]. Rasinski, T., Homan, S. \& Biggs, M. (2008). Teaching reading fluency to struggling readers-methods, materials and evidence. Reading Writing Quarterly, 1-23

[28]. Rasinski.T. , Rikli, A. \& Johnston, S. (2009). Reading fluency: more than automaticity? more than a concern for the primary grades? Literacy Research and Instruction, Vol 48, 350-361. Taylor \& Francis Group

[29]. Rasinski, T. (2013).Supportive fluency instruction: the key to reading success. Reading \& Writing, Center, Kent State University.

[30]. Rasinski,T.\& Padak, N.(2013). From fluency to comprehension powerful instruction through Authentic Reading. Guilford Press

[31]. Rupley, W. H., Blair, T. R. \& Nichols, W. D. (2009). Effective reading instruction for struggling readers: the role of direct/explicit teaching. Reading and Writing Quarterly, 25( 2-3), 125-138.

[32]. Schwanenflugel, P. , Hamilton, A. M., Wisenbaker, J. M. , Kuhn, M. R. \& Stahl, S. (2004). Becoming a fluent reader: reading skill and prosodic features in oral reading of young readers. Journal of Education Psychology, 96( 1), 119-129.

[33]. Schwanenflugel, P. (2008). Fluency development and whole class Instruction: approaches for shared reading. Chapter 3, .41- 77, The Guilford Press,

[34]. Samuels, S. J. (1997). The method of repeated reading. The Reading Teacher, 50(5), 376-381.

[35]. Samuels, S. J. (2002). Reading fluency: Its development and assessment. In Samuels, S. J. \& Farstrup, A. E. (eds), What research has to say about fluency instruction,. International Reading Association. $3^{\text {rd }}$ edition, 166-183.

[36].Samuels, S. J. (2006). Towards a Model of Reading Fluency. In Samuels, S. J. \& Farstrup, A. E. (eds), What Research Has to Say about Fluency Instruction, Chapter, 2, 24- 46, International Reading Association.

[37]. Samuels, S. J. (2012). Reading fluency: its past, present, and future. In Rasinski, T. Blachowicz, C. \& Lems, K. (eds), Fluency Instruction: Research-Based BestPractices, Chapter 1, 7-20, The Guilford Press. 
[38]. Stahl, S. A. \& Heubach, K. M. (2005). Fluency oriented reading instruction. Journal of Litracy Research, 37(1), 25-60.

[39]. Tankersley, K. (2003). The threads of reading: strategies for literacy development. Association for Supervision and Curriculum Development.

[40]. Thornton, P.G. (2008). Effect of modified fluency-oriented reading instruction on african american boys' oral reading fluency and attitude towards reading. (published PHD thesis). Faculty of Auburn University.

[41]. Turner, F. D. (2010). Evaluating the effectiveness of fluency-oriented reading instruction with increasing black and latino reading fluency, as compared to Asian and white second-grade students' reading fluency. The Journal of Negro Education, Vol 79, No. 2, 112-124.

[42]. Tyler, B. J. \& Chard, D. J. (2000). Using readers theater to foster fluency in struggling readers: a twist on the repeated reading strategy. Reading \& Writing Quarterly, Vol 16, 163-168.

[43].Valle, A., Binder, K., Walsh, C., \& Nemier, C. (2013). Eye movements, prosody, and word frequency among average and high skilled second grade readers. School Psychology Review, 42(2), 171-190. 